\title{
Perspectiva de género como factor influyente en la re victimización en delitos de violencia familiar
}

Gender perspective as an influencing factor in re-victimization in crimes of family violence

Perspectiva de gênero como fator influenciador na revitimização em crimes de violência familiar

Artículo recibido en julio 2020

Arbitraje en agosto 2020

Aceptación en septiembre 2020

Publicación en octubre 2020
Zulema Mariana Sainz James

zusainzjames@gmail.com

https://orcid.org/0000-0003-0634-8262

Universidad Andina Simón Bolívar. Sucre, Bolivia
RESUMEN

\section{ABSTRACT}

RESUMO
El presente documento tuvo por objetivo general identificar conductas de re victimización de los operadores de Justicia, fiscales, funcionarios del SLIM y FELC-V a través de la aplicación de escala Samanto. La metodología que se empleó fue de tipo exploratoria, con un enfoque mixto, y un diseño de corte transversal. Los métodos usados fueron: analítico, sintético, deductivo e inductivo. La técnica e instrumento para la recolección de datos fue la encuesta y el cuestionario. La población estuvo conformada por 87 operadores, administradores de justicia. Y la muestra solo de 27. Se determinó que efectivamente los operadores y administradores de justicia generan re victimización en el municipio Sucre. Se concluyó que los protocolos de atención a la víctima tienen disposiciones que pretenden evitar esta. re victimización que se genera a partir de la falta de enfoque de género en los funcionarios.

Palabras clave: Género; violencia familiar; ley 1674; ley 348; re victimización; derecho

The general objective of the investigation is to identify re-victimization behaviors of Justice operators, prosecutors, SLIM and FELC-V officials through the application of the Samanto scale. The methodology used was exploratory, with a mixed approach, and a cross-sectional design. The methods used were analytical, synthetic, deductive and inductive. The technique and instrument for data collection was the survey and the questionnaire. The population was made up of 87 operators, administrators of justice. And the sample of only 27 . It was determined that effectively the operators and administrators of justice generate re-victimization in the Sucre municipality. Therefore, it is concluded that the victim care protocols have provisions that seek to avoid this. re-victimization that is generated from the lack of a gender approach in the civil servants.

Key words: Gender; domestic violence; law 1674; law 348; re victimization; right

O objetivo geral da investigação é identificar comportamentos de revitimização de operadores de Justiça, procuradores, funcionários do SLIM e da FELC-V por meio da aplicação da escala de Samanto. A metodologia utilizada foi exploratória, com abordagem mista e delineamento transversal. Os métodos utilizados foram analítico, sintético, dedutivo e indutivo. A técnica e instrumento de coleta de dados foi o survey e o questionário. A população era composta por 87 operadores, administradores de justiça. E a amostra de apenas 27. Verificou-se que efetivamente os operadores e administradores da justiça geram revitimização no município de Sucre. Portanto, conclui-se que os protocolos de atendimento às vítimas apresentam disposições que procuram evitá-lo. revitimização que é gerada pela falta de uma abordagem de gênero nos funcionários públicos.

Palavras-chave: Gênero; violência familiar; lei 1674; lei 348; revitimização; dereito 


\section{INTRODUCCIÓN}

La violencia de género como la agresión física, psicológica y otras que se ejerce contra las mujeres por el hecho de serlo, y que puede llegar al feminicidio, no es un fenómeno nuevo ni aislado, es más bien un mal histórico que afecta a todas las mujeres, de diversas formas y en distintos grados, desde temprana edad hasta la edad adulta, sin distinguir color, edad, orientación sexual, identidad de género, origen, ni discriminar por raza, cultura, educación, trabajo, clase ni nacionalidad.

La violencia contra las mujeres que se vive en Bolivia, es un fenómeno generalizado que se sufre en casi todas las sociedades con sus particularidades y en diferentes magnitudes, en Latinoamérica y en el país con proporciones alarmantes.

La Ley 1674, Ley Contra la Violencia en la Familia o Doméstica, promulgada el 15 de diciembre de 1995, es la primera ley, el cual marcó un hito muy importante en el tema al derogar el artículo 276, vigente hasta entonces en el Código Penal, que establecía que una mujer no podía denunciar a su esposo o concubino por las agresiones que éste le causara. Mientras que la Ley 348, Ley Integral para Garantizar a las Mujeres una Vida Libre de Violencia, es la segunda ley promulgada en Bolivia que busca incidir en la violencia contra las mujeres.

En la gestión 2013, después de la promulgación de la Ley N. ${ }^{\circ}$ 348, la fiscalía general del Estado reportó 10.058 denuncias de violencia contra la mujer a nivel nacional, de las cuales 1.060 corresponden a Chuquisaca, y de éstos, 859 son casos de violencia familiar.

Bolivia, como parte de su proceso de reflexión y de acuerdo a compromisos internacionales, el 9 de marzo de 2013 de promulgó la Ley 348, Ley integral para garantizar a las mujeres una vida libre de violencia, y posteriormente el Decreto Supremo 2145, el 13 de octubre de 2014, que la reglamenta.

Estas normas establecen como prioridad nacional la erradicación de la violencia en razón de género y definen medidas, mecanismos e instancias para lograrlo entre ellos los operadores de Justicia.

En la actualidad los delitos tipificados por la Ley 348 "Ley Integral Para Garantizar a las Mujeres una Vida Libre de Violencia" son procesados conforme al actual Código de Procedimiento Penal Boliviano, Ley 1970, vale decir, como cualquier otro tipo de delito, a pesar que la ley prevé el acortar los plazos dejando los mismos a discreción del fiscal de materia.

En este orden de ideas, la Ley 348 prevé la creación de juzgados especializados, donde recién en la gestión 2019 se crearon dos juzgados especializados en la ciudad de Sucre, después de seis años de la promulgación de la ley, los cuales son mixtos de violencia contra la mujer y anti corrupción, tanto Jurisdiccional como de apoyo Jurisdiccional conforme establece el artículo 68. de la ley. Sin embargo, no cuentan con equipos interdisciplinarios. 
Teniendo en la aplicación todas las etapas del procedimiento penal, vale decir etapa preliminar, etapa preparatoria y juicio Oral, lo que conlleva a que un proceso por ejemplo de violencia familiar o doméstica pueda llevar incluso tres años.

El procedimiento común implica un peregrinaje para las mismas, ya que, se convierte en un rebotar entre las instituciones promovedoras de denuncia como por ejemplo, el SLIM (Servicio Legal Integral Municipal) y las Instituciones receptoras de denuncia como lo es, la Fiscalía y la FELCV (Fuerza especial de lucha contra la violencia), siendo que la víctima, debe contar su historia en cada institución, enfrentar a funcionarios que no están sensibilizados con la temática, recibir malos tratos e inclusive reproches, aunado a ello, al estado emocional que el hecho de violencia desencadena en la misma, por lo que, se tiene un proceso destinado al fracaso. Hecho que es muy bien aprovechado por la defensa del denunciado, quien accede fácilmente a una conciliación o en su mayoría rechazos dejando a la víctima en estado de indefensión nuevamente en condición de vulnerabilidad respecto a su agresor.

De esta manera, la investigación tuvo por objetivo principal identificar conductas de re victimización de los operadores de Justicia, fiscales, funcionarios del SLIM y FELC-V a través de la aplicación de escala Samanto para medir actitudes de los operadores de justicia hacia las víctimas de delitos de violencia familiar o doméstica atendidas.

Dentro de la presente investigación es necesario realizar un estudio del proceso penal aplicado a los delitos de violencia contra la mujer, si existe perspectiva de género en los operadores de justicia, realizando un análisis de todas y cada una de las etapas del proceso, desarrollo y aplicación del mismo, identificando en dicho estudio y análisis la intervención de los Juzgados de Instrucción Anticorrupción y Violencia Contra la Mujer de la Capital como el ente encargado de precautelar por los derechos fundamentales, Ministerio Público como director de la investigación y las instituciones promovedoras de denuncia como son los SLIM'S Y FELC-V.

\section{Referentes teóricos}

\section{Revictimización}

Según Sánchez, define revictimización, victimización secundaria o doble victimización, como el proceso mediante el cual se produce un sufrimiento añadido por parte de instituciones y profesionales encargados de prestar atención a la víctima (ya sea de malos tratos o violencia de género, secuestros, abusos sexuales, etc) a la hora de investigar el delito o instruir las diligencias oportunas en el esclarecimiento de lo ocurrido: jueces, policías o abogados entre muchos otros (Sánchez, 2018).

Según, la Ley 348 en su artículo 33 se hace una referencia la re victimización como, los procedimientos judiciales o administrativos de protección a mujeres en situación de violencia deberán aplicar el principio de trato digno contenido en la presente Ley, bajo responsabilidad en casos de inobservancia (Ley 348, 2013). 


\section{Violencia}

La Organización Mundial de la Salud (OMS), define a la violencia como el uso intencional o deliberado de la fuerza física o el poder, ya sea en grado de amenaza o efectivo, contra uno mismo, otra persona o un grupo o comunidad, que cause o tenga muchas probabilidades de causar lesiones, muerte, daños psicológicos, trastornos del desarrollo o privaciones, a su vez, estas se subdividen para reflejar tipos de violencia más específicos, y también se toma en cuenta la naturaleza de estos actos violentos: física, sexual, psíquica, privaciones o descuido (Krug, Dahlberg, Mercy, Zwi y Lozano, 2002).

En Bolivia, la vigente Ley Integral para Garantizar a las Mujeres una Vida Libre de Violencia (Ley 348,2013 ), respecto a la violencia contra la mujer indica en su Artículo 6 ,

Constituye cualquier acción u omisión, abierta o encubierta que cause la muerte, sufrimiento o daño físico, sexual, psicológico a una mujer u otra persona, le genere perjuicio en su patrimonio, en su economía, en su fuente laboral, o en otro ámbito cualquiera, por el sólo hecho de ser mujer.

\section{Violencia hacia la mujer}

Según la Organización de Naciones Unidades, la violencia contra las mujeres es de muchas formas: física, sexual, psicológica y económica. Estas formas de violencia se interrelacionan y afectan a las mujeres desde el nacimiento hasta la edad mayor, algunos tipos de violencia, como el tráfico de mujeres, cruzan las fronteras nacionales.

Las mujeres que experimentan violencia sufren de una variedad de problemas de salud y se disminuye su capacidad para participar en la vida pública, la violencia contra las mujeres afecta a familias y comunidades de todas las generaciones y refuerza otros tipos de violencia prevalecientes en la sociedad.

La violencia contra las mujeres también agota a las mujeres, a sus familias, comunidades y naciones, la cual no se confina a una cultura, región o país específico, ni a grupos particulares de mujeres en la sociedad, las raíces de la violencia contra la mujer yacen en la discriminación persistente contra las mujeres.

\section{La víctima como sujeto de derecho}

En el código penal boliviano se define a la víctima como:

A las personas directamente ofendidas por el delito. Al cónyuge o conviviente, a los parientes dentro del cuarto grado de consanguinidad o segundo de afinidad, al hijo o padre adoptivo y al heredero testamentario, en los delitos cuyo resultado sea la muerte del ofendido. A las personas jurídicas en los delitos 
que les afecten. A las fundaciones y asociaciones legalmente constituidas, en aquellos delitos que afecten intereses colectivos o difusos, siempre que el objeto de la fundación o asociación se vincule directamente con estos intereses (Código de Procedimiento Penal Boliviano, 2010).

La víctima podrá promover la acción penal mediante querella, sea en los casos de acción pública o privada, según los procedimientos establecidos en este Código, los menores de edad y los interdictos declarados, podrán formular querella por medio de sus representantes legales.

\section{Perspectiva de género}

La perspectiva de género cuestiona el paradigma construido a partir de un ser humano neutral y universal, que tiene como base al hombre blanco, heterosexual, adulto sin discapacidad, no indígena, así como los roles que a dicho paradigma se le atribuyen. De ello se desprende que la perspectiva de género no sólo está destinada a las mujeres, sino también las personas que tienen diversos contextos y necesidades, también cuestionan la "masculinidad" edificada a partir de dichos parámetros, que asigna roles, conductas y actitudes a los hombres, discriminándolos cuando las expectativas asignadas socialmente no son cumplidas. (Órgano Judicial, 2018).

\section{Violencia hacia la mujer en Bolivia}

En un panorama global, en Bolivia siete de cada 10 mujeres sufrió violencia física en algún momento de su vida. En un rastreo de los datos de ONU Mujeres y de la encuesta de prevalencia y características de la violencia contra las mujeres del 2016, la mayor cantidad de las víctimas que denuncian violencia contra la mujer tiene entre 29 y 59 años de edad, de las denunciantes, el $67,6 \%$ hace una demanda formal, de aquel porcentaje el $56,4 \%$ no obtiene sanción y solo se da una sentencia penal al $35 \%$ de los casos.

De acuerdo a ley 348 para Garantizar a las Mujeres una Vida Libre de Violencia, se identifican 17 tipos de violencia contra las mujeres, entre las que destacan la violencia física, feminicida, psicológica, mediática, simbólica, sexual, patrimonial, económica y laboral, entre otras. La violencia política se trata de manera específica en la ley 243 Contra el Acoso y la Violencia Política hacia las Mujeres. (ONU, 2016).

No obstante, en la realidad, estas formas de violencia no se presentan solas, el $39 \%$ de las mujeres afirma haber sufrido violencia psicológica, el 20,7\% violencia física, el 15,3\% violencia sexual y el 15,1 violencia económica, según datos extraídos del Ministerio de Justicia y el Instituto Nacional de Estadística (2017). Las mujeres sufren violencia sexual en gran medida por agresiones de sus parejas, el 44\% de las mujeres casadas o en unión libre. En 2016 declaraba sufrir violencia en su relación de pareja, de las mujeres solteras el 51,9\% fue agredida alguna vez, en datos del mismo año, el $21,2 \%$ de las solteras afirmaba haber sufrido de violencia sexual. 
Cabe destacar que del total de 113.269 denuncias de violencia contra la mujer procesadas entre 2016 y 2019 (enero a marzo), sólo 1.284 casos recibieron conclusión condenatoria, ósea el $1.13 \%$ de los casos. Sólo 220 de los casos de feminicidio cuentan con sentencia condenatoria, 324 están en proceso y 11 fueron "recalificados o anulados".

Desde la promulgación de la Ley contra la Trata y Tráfico de Personas hubo un registro de alrededor de 3000 casos entre 2012 y 2017, de los que sólo 31 tuvieron condena, en promedio, solo el $1,03 \%$ de los casos fueron resueltos, sin tomar en cuenta las absoluciones.

\section{Violencia hacia la mujer en Sucre}

En 2017, el Ministerio Público registró 10 feminicidios en Chuquisaca y en el primer semestre de 2018, cuatro, aunque no existen datos centralizados y analizados sobre la violencia contra las mujeres en Chuquisaca, organizaciones que trabajan por los derechos humanos de las mujeres en este departamento advierten que la incidencia es alta, pero que su denuncia es muy baja y su reparación, mínima (Noya, 2018).

El estudio "Incidencia de la violencia contra la mujer en el municipio de Sucre" fue realizado sólo en la capital; sin embargo, es considerado una referencia de lo que podría ocurrir en el departamento, este estudio reveló en 2016 que 9 de cada 10 mujeres sufren algún tipo de violencia de parte de sus parejas y que sólo 2 los denuncian. La investigación fue realizada por el Centro Juana Azurduy 10 años después de una primera indagación de las mismas características. Entonces (2006), los resultados apuntaban que 7 de cada 10 mujeres sufren violencia en manos de sus parejas y de ellas, sólo una denunciaba el hecho.

MÉTODO

El estudio se desarrolló con un tipo de metodología exploratoria, pues el problema de la investigación ha sido poco estudiado. Además se utilizó un enfoque mixto, cuali-cuantitativo, ya que se interesó por fenómenos y experiencias humanas enfatizando el estudio de los procesos y de los significados. Bajo un diseño de corte transversal.

Los métodos que se usaron para el desarrollo de la investigación fueron; analítico, sintético, deductivo e inductivo.

Analítico. Este método ayudó a la realización del diagnóstico determinando la situación actual de las mujeres víctimas de violencia que no lograron acceder a una justicia eficaz, determinando las faltas, defectos u omisiones que los operadores de justicia cometen generando re victimización.

Sintético. Este método ayudó a saber sobre las dificultades que existen en el derecho procesal penal en la generación de justicia para las mujeres víctimas de violencia doméstica o de pareja.

Deductivo. Este método se empleó en la deducción de información que ayudó a la comprensión de, la re victimización en los procesos judiciales del municipio de Sucre, denotando las falencias del actual proceso, y a la situación social, económica, psicológica de las mujeres víctimas de violencia. 
Inductivo. Se utilizó para realizar generalizaciones a partir de información obtenida de una muestra representativa de población que, posibilito generalizar las conductas de re victimización y la adopción de la perspectiva de género en funcionarios públicos administradores de justicia.

Las técnicas empleadas para la recolección de datos fue la encuesta y como instrumento se utilizó el cuestionario.

La población estuvo conformada por 87 operadores, administradores de justicia y 3 expertos. Mientras que la muestra que se usó para el estudio fue, de 3 expertos penalistas y expertos en perspectiva de género que actualmente litigan y trabajan con mujeres en situación de violencia. Además de 26 administradores de justicia y operadores que forman parte de SLIM, Fiscalía departamental, Juzgados especializados en violencia contra las mujeres y FELC-V.

\section{RESULTADOS}

Se aplicó la escala Samanto, la cual está compuesta por la dimensión víctima que contienen tres (3) categorías, la Primera categoría: componente cognitivo, incluye indicadores de los pensamientos como lo son las opiniones, ideas, creer que, razonar, suponer, imaginar, entre otras que hacen parte de una actitud revictimizante, Segunda categoría: componente afectivo, segundo elemento de la actitud que alude a los sentimientos, afectos, sensaciones, sensibilidad, piedad, ternura, delicadeza y emociones que se asocian a la revictimización, Tercera categoría: componente conductual o conativo, que hace alusión a manifestaciones abiertas de comportamiento, topografía conductual y proceder, por medio de la escala Samanto se midió las actitudes de los operadores jurídicos hacia la víctima.

\section{Presentación de los resultados colectivos de la investigación}

Como se puede apreciar en la Tabla 1, de los 26 administradores y operadores de justicia encuestados, el 31\% de ellos comprende las edades de 18 a 24 años, un $27 \%$ las edades de 25 a 31 años, un $23 \%$ las edades de 32 a 38 años de edad y las personas en el rango de las edades de 39 a más años solo conforman el $17 \%$.

Tabla 1. Edad.

\begin{tabular}{lcc}
\hline \multicolumn{1}{c}{ ALTERNATIVAS } & FRECUENCIA & PORCENTAJE \\
\hline De 18 a 24 años & 8 & $31 \%$ \\
De 25 a 31 años & 7 & $27 \%$ \\
De 32 a 38 años & 6 & $23 \%$ \\
De 39 a 45 años & 4 & $15 \%$ \\
De 46 a 52 años & 3 & $12 \%$ \\
De 53 a más años & 0 & $0 \%$ \\
$\quad$ Total & $\mathbf{2 6}$ & $\mathbf{1 0 0 \%}$ \\
\hline
\end{tabular}


En la Tabla 2, de los 26 administradores y operadores de justicia encuestados, el $62 \%$ de estos son de género femenino y $38 \%$ del género masculino.

Tabla 2. Género.

\begin{tabular}{lccc}
\hline \multicolumn{2}{c}{ ALTERNATIVAS } & FRECUENCIA & PORCENTAJE \\
\hline Femenino & & 16 & 61,5 \\
Masculino & & 10 & 38,5 \\
& Total & $\mathbf{2 6}$ & $\mathbf{1 0 0 , 0}$ \\
\hline
\end{tabular}

En la Tabla 3 se muestra que, de los 26 administradores y operadores de justicia encuestados, el $27 \%$ de estos pertenece a la Policía Nacional trabajando específicamente en al FELCV, otro $42 \%$ de los encuestados labora en la fiscalía departamental de Chuquisaca, un $19 \%$ de los encuestados trabaja bajo las dependencias del Servicio Legal Integral Municipal (SLIM), y el $11 \%$ labora en los juzgados especializados de violencia contra la mujer.

Tabla 3. Institución a la que pertenece .

\begin{tabular}{|c|c|c|}
\hline ALTERNATIVAS & FRECUENCIA & PORCENTAJE \\
\hline Policía Boliviana & 7 & 26,9 \\
\hline Fiscalía & 11 & 42,3 \\
\hline SLIM & 5 & 19,2 \\
\hline Juzgados & 3 & 11,5 \\
\hline De 53 a más años & 0 & $0 \%$ \\
\hline Total & 26 & $100 \%$ \\
\hline
\end{tabular}

\section{Componentes cognitivos}

Seguido se muestra en la Tabla 4, la cantidad de 8 dimensiones (ítems) referentes a los componentes cognitivos.

Tabla 4. Cognitivos.

\begin{tabular}{|c|c|c|c|c|c|c|c|c|}
\hline ALTERNATIVA & Ítem 1 & Ítem 2 & Ítem 3 & Ítem 4 & Ítem 5 & Ítem 6 & Ítem 7 & Ítem 8 \\
\hline Totalmente de acuerdo & $15 \%$ & $8 \%$ & $42 \%$ & $0 \%$ & $27 \%$ & $0 \%$ & $4 \%$ & $12 \%$ \\
\hline Acuerdo & $69 \%$ & $23 \%$ & $38 \%$ & $42 \%$ & $50 \%$ & $38 \%$ & $69 \%$ & $50 \%$ \\
\hline Desacuerdo & $12 \%$ & $50 \%$ & $15 \%$ & $50 \%$ & $19 \%$ & $54 \%$ & $23 \%$ & $31 \%$ \\
\hline Totalmente en desacuerdo & $4 \%$ & $19 \%$ & $4 \%$ & $8 \%$ & $4 \%$ & $8 \%$ & $4 \%$ & $8 \%$ \\
\hline Total & $100 \%$ & $100 \%$ & $100 \%$ & $100 \%$ & $100 \%$ & $100 \%$ & $100 \%$ & $100 \%$ \\
\hline
\end{tabular}


Ítem 1. La víctima no narra bien los sucesos del delito.

De los 26 administradores y operadores de justicia encuestados, un $69 \%$ se encuentra de acuerdo en la afirmación de que la víctima no narra bien los sucesos del delito o la acción violenta, un $15 \%$ se encuentra totalmente de acuerdo con esta afirmación, y un $16 \%$ niega que la víctima narre de manera inadecuada los sucesos del acto belicoso.

Ítem 2. La mayoría de los delitos se cometen por imprudencia de la víctima.

De los 26 administradores y operadores de justicia encuestados, el 50\% se encuentra en desacuerdo con la afirmación que la mayoría de los delitos se cometen por imprudencia de la víctima, un $19 \%$ se encuentra totalmente en desacuerdo y el $29 \%$ de los operadores de justicia consideran que la víctima es la causante de la acción violenta, siendo que un $8 \%$ está totalmente convencido que son las victimas las culpables del acto violento.

Ítem 3. La víctima espera que los servidores públicos les hagan todo el papeleo del proceso.

Como se puede apreciar en la Tabla 4, de los 26 administradores y operadores de justicia encuestados, el $42 \%$ se encuentran totalmente de acuerdo con la afirmación que la víctima espera que los servidores públicos les hagan todo el papeleo del proceso, un $39 \%$ se encuentra de acuerdo y tan solo un $19 \%$ considera que la víctima se encuentra consiente que es ella la que debe dar seguimiento a su proceso.

Ítem 4. La víctima se quiere aprovechar del sistema judicial.

En la Tabla 4, de los 26 administradores y operadores de justicia encuestados, el $50 \%$ se encuentra en desacuerdo con la afirmación que la víctima se quiere aprovechar del sistema judicial, un $42 \%$ se encuentra de acuerdo con la afirmación.

Ítem 5. La falta de cooperación de la víctima lentifica el proceso.

De los 26 administradores y operadores de justicia encuestados, el $50 \%$ se encuentra de acuerdo con la afirmación la falta de cooperación de la víctima lentifica el proceso judicial, un $27 \%$ se encuentra totalmente de acuerdo con esta afirmación y tan solo el $23 \%$ de los operadores y administradores de justicia tienen una percepción negativa respecto a la afirmación. 
Ítem 6. Las víctimas que se atienden son manipuladoras.

Se muestra que de los 26 administradores y operadores de justicia encuestados, el $54 \%$ de estos se encuentran en desacuerdo con la afirmación "Me parece que las víctimas que atiendo son manipuladoras", un $8 \%$ totalmente en desacuerdo y un $38 \%$ considera que las mujeres que denuncian violencia familiar son manipuladoras.

Ítem 7. La prolongación de los silencios en el relato de la víctima, hace que se disminuya la confiabilidad en su testimonio.

Se muestra que, de los 26 administradores y operadores de justicia encuestados, el $69 \%$ de estos se encuentran de acuerdo con la afirmación "Me da la impresión que la prolongación de los silencios en el relato de la víctima, hace que se disminuya la confiabilidad en su testimonio", un $4 \%$ totalmente de acuerdo, un $23 \%$ se encuentra en desacuerdo y otro $4 \%$ totalmente en desacuerdo con la afirmación.

Ítem 8. La falta de paciencia de la víctima hacia los funcionarios judiciales.

Como se puede apreciar en la Tabla 4, de los 26 administradores y operadores de justicia encuestados, el $50 \%$ de estos se encuentra de acuerdo con la afirmación "Reconozco que me incomoda la falta de paciencia de la víctima hacia los funcionarios judiciales", un $11 \%$ se encuentra totalmente de acuerdo, y un 39\% de los encuestados rechaza la afirmación ya que se encuentran en desacuerdo o totalmente en desacuerdo.

\section{Componente afectivo}

En el siguiente apartado se presenta los resultados obtenidos de la aplicación de la escala SAMANTO en su dimensión afectividad.

Tabla 5. Afectividad.

\begin{tabular}{|c|c|c|c|c|c|c|c|c|c|}
\hline ALTERNATIVA & Ítem 9 & Ítem 10 & Ítem 11 & Ítem 12 & Ítem 13 & Ítem 14 & Ítem 15 & Ítem 16 & Ítem 17 \\
\hline $\begin{array}{l}\text { Totalmente de } \\
\text { acuerdo }\end{array}$ & $4 \%$ & $19 \%$ & $15 \%$ & $15 \%$ & $23 \%$ & $19 \%$ & $46 \%$ & $23 \%$ & $4 \%$ \\
\hline Acuerdo & $65 \%$ & $27 \%$ & $38 \%$ & $19 \%$ & $42 \%$ & $46 \%$ & $50 \%$ & $58 \%$ & $27 \%$ \\
\hline Desacuerdo & $27 \%$ & $42 \%$ & $35 \%$ & $50 \%$ & $19 \%$ & $23 \%$ & $4 \%$ & $19 \%$ & $62 \%$ \\
\hline $\begin{array}{l}\text { Totalmente en } \\
\text { desacuerdo }\end{array}$ & $4 \%$ & $12 \%$ & $12 \%$ & $15 \%$ & $15 \%$ & $12 \%$ & $0 \%$ & $0 \%$ & $8 \%$ \\
\hline Total & $100 \%$ & $100 \%$ & $100 \%$ & $100 \%$ & $100 \%$ & $100 \%$ & $100 \%$ & $100 \%$ & $100 \%$ \\
\hline
\end{tabular}


Ítem 9. La empatía con la víctima contribuye a dilatar el proceso, generando compromiso al operador judicial.

Como se puede apreciar en la tabla de los 26 administradores y operadores de justicia encuestados, el $69 \%$ de esto acepta la afirmación "Siento que la empatía con la víctima contribuye a dilatar el proceso, generando compromiso al operador judicial" y un 31\% rechaza la afirmación.

Ítem 10. Impaciencia por el tiempo perdido tras hacer la misma pregunta a la víctima.

Como se puede observar en la tabla, de los 26 administradores y operadores de justicia encuestados, el $42 \%$ de esto se encuentra en desacuerdo con la afirmación "Me impacienta perder tiempo repitiendo una y otra vez la misma pregunta a la víctima", un $12 \%$ se encuentra en total desacuerdo alcanzando de esta manera un rechazo por el $54 \%$, en cuanto a las personas que se encuentran de acuerdo y totalmente de acuerdo con la afirmación representan el $27 \%$ y $19 \%$ respectivamente.

Ítem 11. Indiferencia ante tantas manifestaciones de tristeza que se ve todos los días.

Como se puede apreciar en la tabla, de los 26 administradores y operadores de justicia encuestados, el $38 \%$ de estos se encuentra de acuerdo con la afirmación, "me he vuelto indiferente ante tantas manifestaciones de tristeza que veo todos los días" a este porcentaje se suma el $15 \%$ que se encuentran totalmente de acuerdo y el $46 \%$ rechazan la afirmación indicando que no son indiferentes ante manifestaciones de tristeza por parte de la mujer víctima de violencia.

Ítem 12. La comprensión hacia la víctima es inútil, porque lo hecho, hecho está.

En la tabla se devela que de los 26 administradores y operadores de justicia encuestados, el $65 \%$ de estos rechaza la afirmación, "algunas veces siento que tanta comprensión hacia la víctima es inútil, porque lo hecho, hecho esta" estando un $50 \%$ en desacuerdo y un $15 \%$ en total desacuerdo, en cuanto al porcentaje que acepta la afirmación es representa el $35 \%$ siendo que $19 \%$ se encuentra de acuerdo y un $16 \%$ totalmente de acuerdo.

Ítem 13. Demostrar compasión a la víctima, entorpece la función investigativa de los operadores judiciales.

Como se puede apreciar en la tabla, de los 26 administradores y operadores de justicia encuestados, el $42 \%$ de estos se encuentra de acuerdo con la afirmación "siento que demostrar compasión a la víctima, entorpece la función investigativa de los operadores judiciales", un $23 \%$ se encuentra totalmente de acuerdo, un $19 \%$ se encuentra en desacuerdo y un $15 \%$ se encuentra en total desacuerdo. 
Ítem 14. Atender a la víctima sin tanta consideración para contribuir en su pronta recuperación.

En cuanto a lo que se visualiza en la tabla, el análisis respecto a la afirmación, "prefiero atender a la víctima sin tanta consideración para contribuir en su pronta recuperación" muestra que, de los 26 administradores y operadores de justicia encuestados, el $65 \%$ de estos acepta la afirmación y un $35 \%$ la rechaza.

Ítem 15. La víctima lograra comprender que todo proceso tiene un protocolo, por ello se requiere de paciencia para esclarecer la verdad.

Como se puede apreciar en la tabla, el análisis respecto a la afirmación, "quisiera que la víctima lograra comprender que todo proceso tiene un protocolo, por ello se requiere de paciencia para esclarecer la verdad" muestra que, de los 26 administradores y operadores de justicia encuestados, el $94 \%$ de estos acepta la afirmación indicando que muchas veces les paso este acontecimiento y tan solo el $4 \%$ rechaza la afirmación.

Ítem 16. Es necesario mantener la distancia con la victima para evitar cualquier expresión de afectiva.

Como se puede apreciar en la tabla, el análisis de la afirmación, "yo siento que con la víctima es necesario mantener la distancia para evitar cualquier expresión de afectiva" muestra que, de los 26 administradores y operadores de justicia encuestados, el $81 \%$ acepta la afirmación y tan solo el $19 \%$ la rechaza, mostrando que muchos de los operadores de justicia no cuentan con la perspectiva de género.

Ítem 17. Me he vuelto indiferente con la víctima, porque siento que es manipuladora, quejumbrosa; además, se lamentan con el propósito de despertar compasión en los operadores judiciales.

En la tabla, el análisis de la afirmación, "me he vuelto indiferente con la víctima, porque siento que es manipuladora, quejumbrosa; además, se lamentan con el propósito de despertar compasión en los operadores judiciales" muestra que, de los 26 administradores y operadores de justicia encuestados, el $61 \%$ de estos se encuentra en desacuerdo, un $8 \%$ se encuentra en total desacuerdo y tan solo el $31 \%$ acepta la afirmación están de acuerdo un $27 \%$ y totalmente de acuerdo $4 \%$. 


\section{Componente conativo}

En el siguiente apartado se presenta los resultados obtenidos de la aplicación de la escala Samanto en su dimensión Conativa.

Tabla 6. Conativo.

\begin{tabular}{|c|c|c|c|c|c|c|c|c|c|}
\hline ALTERNATIVAS & Ítem 18 & Ítem 19 & Ítem 20 & Ítem 21 & Ítem 22 & Ítem 23 & Ítem 24 & Ítem 25 & Ítem 26 \\
\hline $\begin{array}{l}\text { Totalmente de } \\
\text { acuerdo }\end{array}$ & $23 \%$ & $23 \%$ & $23 \%$ & $19 \%$ & $19 \%$ & $19 \%$ & $19 \%$ & $8 \%$ & $15 \%$ \\
\hline Acuerdo & $35 \%$ & $54 \%$ & $42 \%$ & $42 \%$ & $46 \%$ & $38 \%$ & $27 \%$ & $42 \%$ & $35 \%$ \\
\hline Desacuerdo & $35 \%$ & $19 \%$ & $31 \%$ & $31 \%$ & $19 \%$ & $38 \%$ & $46 \%$ & $31 \%$ & $38 \%$ \\
\hline $\begin{array}{l}\text { Totalmente en } \\
\text { desacuerdo }\end{array}$ & $8 \%$ & $4 \%$ & $4 \%$ & $8 \%$ & $15 \%$ & $4 \%$ & $8 \%$ & $19 \%$ & $12 \%$ \\
\hline Total & $100 \%$ & $100 \%$ & $100 \%$ & $100 \%$ & $100 \%$ & $100 \%$ & $100 \%$ & $100 \%$ & $100 \%$ \\
\hline
\end{tabular}

Ítem 18. Molestia porque la víctima no disponga de suficiente tiempo, cuando la justicia la requiere para adelantar el proceso.

Se muestra en la tabla el análisis de la afirmación, "me molesta que la víctima no disponga de suficiente tiempo, cuando la justicia la requiere para adelantar el proceso" donde, de los 26 administradores y operadores de justicia encuestados, el $35 \%$ de estos se encuentran de acuerdo con la afirmación al igual que otro $35 \%$ se encuentra en desacuerdo, a estos porcentajes de participación se suma el porcentaje de las personas que se encuentran totalmente de acuerdo con un $23 \%$ alcanzando de esta manera la aceptación de la afirmación en un $58 \%$.

Ítem 19. La víctima no asuma la responsabilidad de su proceso para que éste avance.

En la tabla se muestra el análisis de la afirmación, "me indispone que la víctima no asuma la responsabilidad de su proceso para que este avance" donde, de los 26 administradores y operadores de justicia encuestados, el $54 \%$ de estos se encuentra de acuerdo con la afirmación, un $23 \%$ se encuentra totalmente de acuerdo, el $19 \%$ se encuentra en desacuerdo y tan solo el $4 \%$ se encuentra en total desacuerdo.

Ítem 20. Es molestoso que la víctima no entienda los tiempos del proceso judicial.

Se expresa el análisis de la afirmación, "me resulta molesto que la víctima no entienda los tiempos del proceso judicial" donde, de los 26 administradores y operadores de justicia encuestados, el $42 \%$ de estos se encuentra de acuerdo con la afirmación, un $23 \%$ se encuentra totalmente de acuerdo, un $30 \%$ se encuentra en desacuerdo y tan solo el $4 \%$ se encuentra en total desacuerdo. 
Ítem 21. Resulta incómodo encontrar víctimas que son incoherentes con el relato de los hechos.

Como se puede apreciar en la tabla, de los 26 administradores y operadores de justicia encuestados, el $42 \%$ de estos se encuentra de acuerdo con la afirmación, "a mí me resulta incómodo encontrar víctimas que son incoherentes con el relato de los hechos", un $19 \%$ se encuentra totalmente de acuerdo alcanzando el $61 \%$ de aceptación de la afirmación, y un $38 \%$ de rechazo debido a que el $31 \%$ de estos se encuentran en desacuerdo y un $8 \%$ se encuentra en total desacuerdo.

Ítem 22. A la víctima de carácter frágil, se le debe tratar con firmeza para que entienda el proceso judicial.

En la tabla, de los 26 administradores y operadores de justicia encuestados, el $26 \%$ de estos se encuentra de acuerdo con la afirmación, "tengo la impresión que, a la víctima de carácter frágil, se le debe tratar con firmeza para que entienda el proceso judicial", un $19 \%$ se encuentra totalmente de acuerdo, al igual que las personas que se encuentran en desacuerdo que alcanzan el $19 \%$ y por último se puede observar que el $15 \%$ se encuentra totalmente en desacuerdo.

Ítem 23. Muestra confianza hablándole con dureza a la víctima para que reaccione.

Como se puede apreciar en el tabla, de los 26 administradores y operadores de justicia encuestados, el $38,5 \%$ de estos se encuentra de acuerdo al igual de las personas que se encuentra en desacuerdo con la afirmación, "suelo mostrar confianza en mi experiencia hablándole con dureza a la víctima para que reaccione", a la vez se puede observar que son más las personas que aceptan la afirmación puesto que el porcentaje de personas que se encuentran totalmente de acuerdo con la afirmación alcanzan el $19 \%$ sumados al $39 \%$ que indico estar de acuerdo con la afirmación alcanzan el 58\% del total.

Ítem 24. Molestia porque la víctima no entiende que hay otras personas que necesitan atención jurídica.

Se devela en la tabla que de los 26 administradores y operadores de justicia encuestados, el $46 \%$ de estos se encuentra en desacuerdo con la afirmación, "me disgusta la víctima que no entiende que hay otras personas que necesitan atención jurídica", un $8 \%$ se encuentra en total desacuerdo alcanzando un $54 \%$ de rechazo a la afirmación. Por su parte tenemos al $46 \%$ que muestra aceptación con la variable estando un $27 \%$ de acuerdo y un $19 \%$ totalmente de acuerdo.

Ítem 25. Molestia porque la víctima no entienda que es necesario examinarla cuantas veces sea indispensable de acuerdo al protocolo. 
Como se puede apreciar en la tabla, de los 26 administradores y operadores de justicia encuestados, el $50 \%$ de estos acepta la afirmación, "me molesta que la víctima no entienda que es necesario examinarla cuantas veces sea indispensable de acuerdo al protocolo", al igual que el $50 \%$ de estos rechaza la afirmación, si bien existe una paridad en la aceptación y rechaza de la afirmación se puede observar que son más las personas que se encuentran totalmente en desacuerdo en comparación de las personas que indicaron estar totalmente de acuerdo.

Ítem 26. Desconfianza con la víctima que no habla con seguridad, porque es señal de que está mintiendo.

Como se puede apreciar en la tabla, de los 26 administradores y operadores de justicia encuestados, al igual que en la anterior afirmación existe una paridad en cuanto a la aceptación y rechazo alcanzado el $50 \%$ para cada una, pero se puede observar que son más las personas que se encuentran totalmente de acuerdo con la afirmación "suelo desconfiar de la víctima que no habla con seguridad, porque es señal de que está mintiendo" en comparación con las personas que indicaron estar en total desacuerdo.

Posterior a los resultados y aplicación de la escala de valoración de tipo Likert, se determinó que efectivamente los operadores y administradores de justicia generan re victimización en el municipio Sucre, ya que, tienen una menor tolerancia respecto a los factores afectivos con lo que se podría confirmar que los conceptos sociales frente a las funciones, comportamientos, actividades y atributos que cada sociedad considera apropiados para los hombres y las mujeres, esto quiere decir que, socialmente sigue prevaleciendo una serie de roles que marcan lo que se espera frente al comportamiento del sexo masculino y el sexo femenino, por lo que impide que los operadores y administradores de justicia brinden una atención digna y efectiva a las mujeres víctimas de violencia, esto debido a una alta correlación entre la dimensión afectiva y la re victimización.

\section{CONCLUSIONES}

Se pudo determinar que la falta de perspectiva de género en los funcionarios públicos del sistema judicial genera re victimización, lo cual impide un acceso efectivo a la justicia por parte de las mujeres que sufren violencia. Datos que fueron comprobados con la consulta a expertos en primera instancia donde se determinó el grado de conocimiento de estos sobre la temática y la consulta del impacto que tiene la re victimización en el acceso efectivo a la justicia donde los expertos indican que debido a la re victimización por parte de los funcionarios públicos las mujeres víctimas de violencia deciden desistir de la denuncia, esto debido a que muchas veces son ellas las juzgadas y recriminadas por los funcionarios públicos y al no brindar una atención que se enfoque en el resarcimiento del daño en primera instancia esta deciden desistir.

Por lo tanto, al realizar el diagnóstico se pudo evidenciar la existencia de revictimización en el sistema judicial actual donde el $92 \%$ de los operadores y administradores de justicia ejercen 
re victimización inconscientemente, siendo que sus protocolos de atención a la víctima tienen disposiciones que pretenden evitar esta. $\mathrm{R}$ victimización que se genera a partir de la falta de enfoque de género en los funcionarios públicos puesto que la dimensión afectiva fue la que generó mayor correlación y concentración de los datos respecto a la revictimización.

\section{REFERENCIAS}

Estado Plurinacional de Bolivia (1995). Ley Contra la Violencia en la Familia o Domesticas, Ley 1674. La Paz: Gaceta Oficial del Estado Plurinacional

Estado Plurinacional de Bolivia. (2012) Ley Contra el Acoso y Violencia Política hacia las Mujeres, Ley 243. La Paz: Gaceta Oficial del Estado Plurinacional

Estado Plurinacional de Bolivia (2013). Ley para Garantizar a las Mujeres una vida Libre de Violencias, Ley 348. La Paz: Gaceta Oficial del Estado Plurinacional

Krug, E.; Dahlberg, LL.; Mercy, J.; Zwi A., y Lozano, R. (2002) World report on violence and health. Geneva: World Health Organization; editors

Ministerio de justicia (2010). Código Penal y Código de Procedimiento Penal
Ministerio de Justicia y Derechos Humanos (2013). Trata de personas. Argentina, segunda edición, Editorial Ministerio de Justicia y Derechos Humanos de la nación, Sarmiento 329, C. P. 1041AFF, C.A.B.A

ONU Mujeres (2016). Encuesta de Prevalencia y Características de la Violencia Contra las Mujeres

Órgano judicial (2017) Protocolo para juzgar con perspectiva de género. Comité de género, segunda edición

Sánchez, R (2018) La práctica de la revictimización en el proceso de una denuncia. Recuperado en https://fundacionperiodismo.org/la-practicala-revictimizacion-proceso-una-denuncia/ 